archives

of thermodynamics

Vol. 36(2015), No. 1, 83-92

DOI: 10.1515 /aoter-2015-0006

\title{
Application of the method of data reconciliation for minimizing uncertainty of the weight function in the multicriteria optimization model
}

\author{
BARBARA MENDECKA ${ }^{1}$ \\ JOACHIM KOZIOE
}

Silesian University of Technology, Institute of Thermal Technology,

Konarskiego 22, 44-100 Gliwice, Poland

\begin{abstract}
The multicriteria decision process consists of five main steps: definition of the optimisation problem, determination of the weight structure of the decision criteria, design of the evaluation matrix, selection of the optimal evaluation method and ranking of solutions. It is often difficult to obtain the optimal solution to a multicriterion problem. The main reason is the subjective element of the model - the weight functions of the decision criteria. Expert opinions are usually taken into account in their determination. The aim of this article is to present a novel method of minimizing the uncertainty of the weights of the decision criteria using Monte Carlo simulation and method of data reconciliation. The proposed method is illustrated by the example of multicriterion social effectiveness evaluation for electric power supply to a building using renewable energy sources.
\end{abstract}

Keywords: Multicriteria optimization; Weight uncertainty; Photovoltaics

\section{Nomenclature}

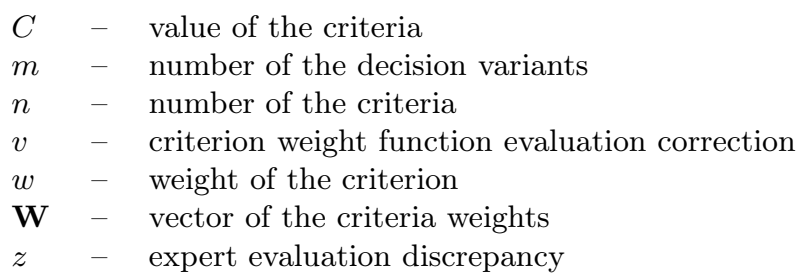

\footnotetext{
${ }^{1}$ Corresponding Author. E-mail: bmendecka@polsl.pl
} 


\section{Greek symbols}

$\Phi \quad-\quad$ objective function

$\lambda-$ Lagrange coefficient

\section{Subscripts}

$i \quad-\quad$ index of the decision variants

$j \quad-\quad$ index of the criteria

$m$ - maximal value of the criteria function

$T-$ minimal value of the criteria function

\section{Introduction}

The decision-making theory is used under the certainty (the decision maker has a complete and certain knowledge on all the necessary input variables), risk (the decision maker has a knowledge on probability distributions of the quantities describing the decision-making process), uncertainty (probability distributions are not known), lack of information and conflict [1].

Sources of uncertainty of decision-making can be grouped in the following categories:

- objective environmental factors, impacting all the decision variants in a similar way, i.e., fluctuations of values of objective (quantitative) criteria;

- objective environmental factors, impacting various decision variants in different ways, i.e., constraints fluctuations;

- subjective environmental factors impacting all the decision variants in a similar way, i.e., the human factor in the decision-making process, multitude of experts evaluating given criterion (criterion weight functions);

- subjective environmental factors impacting various decision variants in different ways, i.e., fluctuations of subjective (qualitative) criteria.

In the decision-making process under uncertainty conditions, two approaches can be distinguished based on the game theory (decision-making under the conditions of conflict or competition) and utilising the expert knowledge (experience) $[2,3]$. The first approach is based on conventional criteria [2], e.g., the Laplace criterion (identifying the uncertainty with equal probabilities of all the considered states of nature), MAX-MIN (known as Wald rule), consisting of making a decision whose worst possible outcome is not worse than the best outcome of another decision. The Hurwicz rule 
(taking the caution factor into account), an extension of the MAX-MIN (Wald) rule, and the Bayes criterion (choosing the variant characterised by the largest expectation value of the profit) can also be used. When the knowledge (understood as ability to predict future behaviour) of an expert in the given field or availability of data on the results of decisions made in the past in similar conditions is present, using these information (estimates) on probabilities the uncertainty problem may be reduced to the risk problem [1-3]. The aim of this article is to present a novel method of minimizing the uncertainty of the weights of the decision criteria using the Monte Carlo simulation and a method of data reconciliation. The proposed method is illustrated by the example of multi-criteria social efficiency of energy substitution evaluation for electric power supply to a building using renewable energy sources.

\section{Generic multicriteria optimization approach}

Under consideration is a general discrete multicriteria decision problem, in which the decision maker has determined a finite $m$-elements set of the decision variants and a finite $n$-elements set of the evaluation criteria. The performance of the decision variant in terms of evaluated criteria can be determined on the basis of generic methodology of social efficiency of substitution, fully described in [4-6].

Social efficiency of substitution indicator is defined as a difference between value of the $j$ th evaluation criterion using the reference and $i$ th substitutive variant with respect to unit of substitutive product (where: $i=1,2, \ldots, m ; j=1,2, \ldots, n)$. Criteria values are often characterized by different units. This is why, it is necessary to carry out the normalization of the criteria values. Normalized values of the criteria are calculated using the following expression:

$$
\bar{C}_{i j}=\frac{\Delta C_{i j}}{C_{i j, \text { max }}-C_{i j, \min }} \text { where }\left\{\begin{array}{l}
\Delta C_{i j}=C_{i j}-C_{i j, \text { min }} \text { for benefit criteria } \\
\Delta C_{i j}=C_{i j, \text { max }}-C_{i j} \text { for cost criteria }
\end{array}\right.
$$

where $C_{i j, \max }, C_{i j, \min }$ are the minimal and maximal criteria values.

It is also assumed that the decision maker has determined the weights of the decision criteria (denoted as $w_{j}$ where $j=1,2, \ldots, n$ ).

The next step is to obtain the overall score of $i$ th alternative. The 
aggregated social efficiency is given by the following formula:

$$
\begin{gathered}
\overline{\mathbf{C}}_{i}=\sum_{j=1}^{J} \mathbf{W}^{T} \bar{C}_{i j}, \\
\mathbf{W}=\left\{w \in R: w \geq 0, \sum_{j=1}^{n} w_{j}=1\right\}
\end{gathered}
$$

is a vector of weights of the decision criteria, $T$ denotes the transpose and $R$ is the set of the real numbers.

Finally, a ranking of solutions can be determined. An optimal solution is a variant with the highest value of the aggregated social efficiency indicator.

$$
\bar{C}_{\text {opt }}=\max \left[\bar{C}_{1} \bar{C}_{2} \ldots \bar{C}_{m}\right]^{T} .
$$

\section{$3 \quad$ Using the Monte Carlo method for determining the weights of the decision criteria}

The key issue in decision analysis under the conditions of uncertainty is to use the right quantitative profile of the qualitative (unmeasurable) effects and its probable results under the conditions of uncertainty. The uncertainty regarding actual values of the input variables is typically included in a model by considering the randomness. The random factors in the model represent the quantities present in the real system that cannot be included in a way enabling formulation of deterministic impact on the output values of the real system. Randomness in probabilistic models is expressed by parametres of the given probability distribution [7].

In this study the Monte Carlo method was used for evaluating an aggregated social efficiency indicator, Eq. (2). Monte Carlo technique simulation experiments consist of observing the results obtained using the model. The results are obtained by repeated random choice of input variables values with a random number generator consistent with the theoretically assumed random variable probability distribution. With the Monte Carlo technique, a set of results is obtained, containing randomly chosen input variable values and corresponding experimental outcomes.

In the proposed model, criterion weight function variants are first randomly chosen and then evaluation of the supreme criterion is performed. Weight functions of the criteria are obtained based on evaluations of many 
independent experts. If there were more than 21 experts, the distributions mentioned above could be normal. However, usually the number of experts is lower and the Student's t-distribution is the most suitable [7]. Characterising these distributions by straight line segments also produces good results. Nevertheless, precise determination of the (real) random variable distribution is not always possible. In such a situation it can be at least partially replaced (for the purposes of simulation model design) with such well-known variability measures as expectation value, mean, standard deviation, mean absolute error.

As the values obtained should meet the obvious requirement (3), results of each random choice should be adjusted. For this, methods of the so-called adjustment calculus are suggested [8]. Using the method of data reconciliation for determining the weights of the decision criteria Using the Monte Carlo method, a nonunity weight function sum is obtained. Therefore, the condition (3) is not fulfilled. Fulfilling this condition is a rather improbable chance event. In order to fulfil the obvious condition (3), use of the method of data reconciliation is proposed. For the condition to be met, $v_{j}$ corrections should be included. The following rules emerge: the correction of the given weight should increase with increasing difference between the maximal and minimal weight function expert evaluations. This difference is given by the following formula:

$$
\Delta w_{j}=w_{j \max }-w_{j \min },
$$

where: $\Delta w_{j}$ - evaluation uncertainty of the $j$ th criterion, $w_{j \max }, w_{j \min }-$ maximal and minimal expert evaluations of the $j$ th criterion weight function.

The problem under consideration is than reduced to a limited optimisation function of the form

$$
\Phi=\sum_{j=1}^{n}\left(\frac{v_{j}}{\Delta w_{j}}\right)^{2} \rightarrow \min ,
$$

where: $v_{j}-j$ th criterion weight function evaluation correction.

When solving the problem using indeterminate Lagrange coefficients, a new form of the function under consideration is obtained:

$$
\Phi=\sum_{j=1}^{n}\left(\frac{v_{j}}{\Delta w_{j}}\right)^{2}-\lambda\left(\sum v_{j}-z\right),
$$


where: $z$ - expert evaluation discrepancy $z=\left(\sum w_{j}-1\right)$.

Apart from the correction values, the indeterminate Lagrange coefficient $\lambda$ is also unknown. In the end, solving the equation system, the following relationship is obtained:

$$
v_{j}=\frac{-z \Delta w_{j}}{\sum \Delta w_{j}} .
$$

The algorithms above should be used for each randomly chosen result.

\section{Numerical example}

The numerical example concerns electric energy demand for the purposes of lighting, home appliances power supply and installation power supply for a single-family house. The analysis was performed for a typical household in Poland [9]. The input data for balance calculations are provided in the Tab. 1.

Table 1: Input data for balance calculations.

\begin{tabular}{|l|l|}
\hline Building type & Single-family \\
\hline \hline Useful building area & $75 \mathrm{~m}^{2}$ \\
\hline Annual electric energy demand & $2182.5 \mathrm{kWh}$ \\
\hline Longitude & $19^{\circ} 2^{\prime}$ \\
\hline Latitude & $50^{\circ} 14^{\prime}$ \\
\hline
\end{tabular}

The energy balance calculations were performed using the Analizator OZE programme [19]. The first step was to define the electric energy demand in the building under consideration, using a probabilistic model of the daily profile of recipient's power load, developed on the basis of real-life measurements of energy consumption in a building.

Multicriteria decision analysis of the social efficiency of the energy substitution was conducted for three alternative variants of decision-making. The reference variant bases on the use of electricity from the power grid. A list of the alternative variants of electric power supply to a building are provided in Tab. 2. To multicriteria analysis of electric power supply to a building, three criteria have been proposed, including the economic, ecological and sociological effects. A detailed description of selected criteria is shown in Tab. 3. The criteria presented below are examples, although other criteria could be defined by stakeholders to be applied in the multicriteria 
Table 2: Considered types of electric power supply in a building.

\begin{tabular}{|l|c|c|c|c|}
\hline Type of alternative system & Ref. & I & II & III \\
\hline \hline Number of photovoltaic panels & 0 & 1 & 3 & 10 \\
\hline PV panel power output, kW & 0 & 0.25 & 0.75 & 2.5 \\
\hline Share of renewable energy & 0 & 0.12 & 0.34 & 0.78 \\
\hline \multicolumn{6}{|c|}{ Base energy source - photovoltaic panels } \\
\hline Annual energy production, kWh & 0 & 266 & 750 & 1710 \\
\hline Annual work hours, h & 0 & 4393 & 4393 & 4393 \\
\hline \multicolumn{7}{|c|}{ Peak energy source - electricity from power grid } \\
\hline Annual energy production, kWh & 2182 & 1916 & 1432 & 472 \\
\hline Annual energy production, kWh & 8760 & 8398 & 6154 & 1917 \\
\hline
\end{tabular}

Table 3: Proposed set of the evaluation criteria.

\begin{tabular}{|l|l|l|}
\hline No. & \multicolumn{1}{|c|}{ Evaluation criterion } & \multicolumn{1}{c|}{ Description } \\
\hline \hline 1 & $\begin{array}{l}\text { Unit life cycle cost method- } \\
\text { ology [4] }\end{array}$ & $\begin{array}{l}\text { Economic indicator that takes into account the follow- } \\
\text { ing costs: initial capital, maintenance, energy, depre- } \\
\text { ciation and tax impacts, effects on production, scrap } \\
\text { value, other annual costs (PLN/kWh). }\end{array}$ \\
\hline 2 & $\begin{array}{l}\text { Unit cumulative } \mathrm{CO}_{2} \text { emis- } \\
\text { sion methodology [10] }\end{array}$ & $\begin{array}{l}\text { The sum of the total } \mathrm{CO}_{2} \text { emitted during useful prod- } \\
\text { uct generation }\left(\mathrm{kgCO}_{2} / \mathrm{kWh}\right) .\end{array}$ \\
\hline 3 & $\begin{array}{l}\text { Human health } \\
\text { methodology Ecoindicator } \\
99[10]\end{array}$ & $\begin{array}{l}\text { The sum of years of potential life lost due to prema- } \\
\text { ture mortality and the years of productive life lost due } \\
\text { to disability measured in disability-adjusted life year } \\
\text { DALY (DALY } / \mathrm{kWh).}\end{array}$ \\
\hline
\end{tabular}

analysis. Unit indicators of social effects of the application of a particular way of electric power supply to a building have been determined on the basis of the data contained in Tab. 4. These data have been designated on the basis of the balance calculation.

The next step of the analysis was to determine the performance of social efficiency of energy substitution indicators in accordance with the methodology [4-6]. For the calculation, the unit rates shown in Tab. 5 were used. The results of the calculations of the social efficiency of substitution for each criteria referring to the unit of substitutive energy $\left(\mathrm{kWh}_{e s}\right)$ is contained in Tab. 6 . 
Table 4: Input data for social efficiency of energy substitution analysis.

\begin{tabular}{|l|c|c|c|c|}
\hline & Ref. & I & II & III \\
\hline \hline Investment cost, PLN & 9550 & 22550 & 29600 & 54250 \\
\hline $\begin{array}{l}\text { Operating and maintenace } \\
\text { cost, PLN/a }\end{array}$ & 1205 & 1065 & 815 & 315 \\
\hline $\begin{array}{l}\text { Cumulative } \mathrm{CO}_{2} \text { emission, } \\
\mathrm{kg} / \mathrm{a}\end{array}$ & 2390 & 2100 & 1570 & 520 \\
\hline Human health, DALY/a & $2.60 \times 10^{-4}$ & $2.73 \times 10^{-4}$ & $2.97 \times 10^{-4}$ & $3.45 \times 10^{-4}$ \\
\hline
\end{tabular}

Table 5: Unit values of the criteria.

\begin{tabular}{|l|c|c|c|c|}
\hline & Ref. & I & II & III \\
\hline \hline$e_{1}, \mathrm{PLN} / \mathrm{kWh}$ & 0.77 & 1.01 & 1.06 & 1.41 \\
\hline$e_{2}, \mathrm{kgCO} / \mathrm{kWh}$ & 1.1 & 0.97 & 0.74 & 0.28 \\
\hline$e_{3}, \mathrm{DALY} / \mathrm{kWh}$ & $1.19 \times 10^{-7}$ & $1.25 \times 10^{-7}$ & $1.36 \times 10^{-7}$ & $1.58 \times 10^{-7}$ \\
\hline
\end{tabular}

Table 6: Social efficiency of energy substitution.

\begin{tabular}{|l|c|c|c|c|}
\hline & Ref. & I & II & III \\
\hline \hline$C_{1}, \mathrm{PLN} / \mathrm{kWh}_{e s}$ & 0.00 & -0.24 & -0.29 & -0.64 \\
\hline$C_{2}, \mathrm{kgCO}_{2} / \mathrm{kWh}_{e s}$ & 0.00 & 0.13 & 0.36 & 0.82 \\
\hline$C_{2}, \mathrm{DALY} / \mathrm{kWh}_{e s}$ & 0.00 & $-6.11 \times 10^{-9}$ & $-1.72 \times 10^{-8}$ & $-3.93 \times 10^{-8}$ \\
\hline
\end{tabular}

The next stage of analysis was the normalization of social efficiency of energy substitution indicators of substitution using Eq. (1). The results are presented in Tab. 7.

Table 7: Normalized social efficiency of energy substitution.

\begin{tabular}{|c|c|c|c|c|}
\hline & Ref. & I & II & III \\
\hline \hline $\bar{C}_{1}$ & 1.000 & 0.623 & 0.546 & 0.000 \\
\hline $\bar{C}_{2}$ & 0.000 & 0.156 & 0.439 & 1.000 \\
\hline $\bar{C}_{3}$ & 1.000 & 0.844 & 0.561 & 0.000 \\
\hline
\end{tabular}


Normalized values of social efficiency of energy substitution are in the range from 0 to 1 . A value of 0 means the lowest, and a value of 1 the highest efficient decision variant from the point of view of a given criterion. In order to obtain aggregate indicator of social efficiency of energy substitution the Eq. (3) must be used. As previously mentioned, this step of multicriteria modeling is characterized by the greatest uncertainty associated with the subjective element of the model, namely to preference of decision makers. In order to validate the expert assessments, in particular when in the decisionmaking process shall contribute to many policy-makers, the authors propose to use the original method based on the Monte Carlo simulation, and the use of method of data reconciliation. For this simulation, the normal distributions of the decision maker preferences with its characteristic parameters were considered.

Table 8: Parameters of considered normal distribution of the criteria weight.

\begin{tabular}{|c|c|c|c|c|c|}
\hline & Max & Min & Mean & $\begin{array}{c}\text { Standard } \\
\text { deviation }\end{array}$ & Range \\
\hline \hline$w_{1}$ & 0.60 & 0.30 & 0.450 & 0.0500 & 0.30 \\
\hline$w_{2}$ & 0.40 & 0.30 & 0.350 & 0.0167 & 0.10 \\
\hline$w_{3}$ & 0.25 & 0.00 & 0.125 & 0.0417 & 0.25 \\
\hline
\end{tabular}

Table 9: Obtained parameters of the normal distribution of aggregated social efficiency of energy substitution.

\begin{tabular}{|l|c|c|c|c|c|}
\hline & Max & Min & Mean & $\begin{array}{c}\text { Standard } \\
\text { deviation }\end{array}$ & Range \\
\hline \hline Ref. & 0.700 & 0.528 & 0.638 & 0.017 & 0.143 \\
\hline I & 0.576 & 0.444 & 0.488 & 0.012 & 0.098 \\
\hline II & 0.516 & 0.502 & 0.509 & 0.002 & 0.058 \\
\hline III & 0.424 & 0.300 & 0.362 & 0.017 & 0.124 \\
\hline
\end{tabular}

In the Tab. 9, the simulation results using the proposed method are shown. The highest uncertainty of the aggregated social efficiency of energy substitution is characterized by a reference variant and variant III ( $78 \%$ of solar energy). The smallest uncertainty is characterized by II alternative (34\% share of solar energy). At the confidence level 0.95, the following ranking 
variants can be obtained: Ref-I-II-III. In all probability limit items ranked options (Ref. and III) remain unchanged. The order of the other variants in the ranking varies depending on the level of probability, which evaluated the situation is focus.

\section{Conclusions}

The article presents a new method for minimizing uncertainty of the weight function in a discrete multicriteria optimization model. The uncertainty is particularly important in the case of analyzing subjective elements of the model. The new approach is a combination of the Monte Carlo and data reconciliation methods and can be used to validate the input data on a different confidence level, as well as for the sensitivity analysis.

Acknowledgements The work was supported by Ministry of Science and Higher Education within statutory research funding scheme.

Received 10 December 2014

\section{References}

[1] Piech H.: Multicriteria optimisation on the basis of uncertain knowledge. Czesstochowa University Publishers, 2007 (in Polish).

[2] Szargut J.: Thermodynamic and economic analysis in industrial power engineering. WNT, 1983 (in Polish).

[3] LiU B.: Theory and Practice of Uncertain Programming. Springer Science \& Business Media, 2009.

[4] KozIoŁ J.: Effectiveness assessment method of fuel substitution in applied processes. Arch. Energ. 4(1981), 1, 241-249 (in Polish).

[5] B. Mendecka, Kozioe J.: Evaluation of economic, energy-environmental and societal effects of non-renewable energy substitution with renewable energy sources. Proc. SDEWES Conf., 2013.

[6] MendeckA B.: Substitution of energy in a building: Multi-criteria optimization model based on uncertain data. In: Proc. SDEWES Conf., 2014.

[7] Thomopoulos N.T.: Essentials of Monte Carlo Simulation: Statistical Methods for Building Simulation Models, 2013 Edn. Springer, New York 2012.

[8] Szargut J.: Compensation calculus in heat technology. Ossolineum, 1984 (in Polish).

[9] Energy Consumption in Households in 2009. GUS, Warsaw 2012.

[10] SimaPro. Database Manual. Methods library. 2008. 